\title{
Prevalence and Molecular Identification of Giardiasis Isolates from Stray Dogs in Erbil Province, Kurdistan Region, Iraq
}

\author{
Zuber I. Hassan* \\ Department of Medical Laboratory Techniques, Shaqlawa Technical Institute, Erbil Polytechnic University, Erbil, Kurdistan Region, Iraq
}

\author{
*Corresponding author: \\ Zuber I. Hassan, Department \\ of Medical Laboratory \\ Techniques, Shaqlawa \\ Technical Institute, Erbil \\ Polytechnic University, Erbil, \\ Kurdistan Region, Iraq. \\ E-mail: zuberismail@epu. \\ edu.iq
}

Received: 15 May 2020

Accepted: 19 July 2020

Published: 30 June 2021

DOI

10.25156/ptj.v11n1y2021.pp7-12

\begin{abstract}
A B S TR A C T
Giardia lamblia is the intestinal, flagellated protozoan parasite. It should make a species complex and comprises eight assemblages (A-H). In the current study, out of 153 examined samples, $16(10.46 \%)$ and $36(23.53 \%)$ specimens were positive by concentration and polymerase chain reaction (PCR) technique for giardiasis, respectively. The highest rate of infection was found in a rural area $(14.38 \%)$ than in urban areas $(9.15 \%)$. As well as, the infection rate in males (25/153) was higher compared to that of female dogs $(11 / 153)$. Regarding fecal consistency, the highest rate $(18.3 \%)$ of giardiasis was observed in diarrheic dogs, while the lowest rate of giardiasis $(5.23 \%)$ was observed among non-diarrheic dogs. The PCR products were sequenced for 20 samples and further examined by sequence analysis, 16 isolates under the accession number (MN629930), independent of the host, exhibited G. lamblia GenBank ID: M36728, while in four samples under the accession number (MN629931), nucleotide substitutions generate polymorphism at position 542 and $561(\mathrm{C} \rightarrow \mathrm{T})$ and $(\mathrm{A} \rightarrow \mathrm{G})$ at position 684 . The similarity between MN629931 and AY072723 genotype A2 was $99.9 \%$ which was one nucleotide substitution at position $542(\mathrm{C} \rightarrow \mathrm{T})$. The sequencing of the PCR products recognized two assemblages in dogs suggested the possible role of dogs as the reservoir for human giardiasis in Erbil Province which is the first records in the Kurdistan Region, Iraq.
\end{abstract}

Keywords: Zoonotic giardiasis; Stray dog; Assemblages; Phylogeny; Erbil

\section{INTRODUCTION}

Giardia lamblia (synonyms: Giardia intestinalis and Giardia duodenalis) is a universal and famous enteric protozoan that is present in the intestines of mammalian hosts (Faria et al., 2016). Giardia is a single-celled parasite and frequently causes diarrheal diseases in domestic animals, cats, dogs, and wild lives; this phenomenon is called giardiasis (Hossain et al., 2014). The infection commonly happens by fecal-oral transmission through food and drinking water which is polluted with feces containing the cysts (Pipia et al., 2014, and Al-Difaie, 2016). Clinical demonstrations of giardiasis in dogs are variable, ranging from the lack of symptoms to acute or chronic diarrhea, dehydration, vomiting, abdominal pain, and weight loss (Roointan et al., 2013). Therefore, it becomes the hardest currency to identify giardiasis with signs; because many symptoms have related to the cluster of disease, for example, diarrhea, consistent weight loss, fail to develop strongly, and sometimes death (Gultekin et al., 2017). Diagnosis of Giardia infection with the use of a fecal smear or fecal flotation is difficult because of random cyst shedding and their morphology, small size, and their similarity in appearance to many pseudoparasites such as yeast (Piekarska et al., 2016).
Molecular characterization of G. lamblia is beneficial and mainly used in epidemiological studies. Genotyping of G. lamblia using PCR techniques based on polymorphic genes encoding $18 \mathrm{~S}$ rRNA, glutamate dehydrogenase, triosephosphate isomerase, and $\beta$-giardin (Monis et al., 1999; Caccio et al., 2005; and Piekarska et al., 2016). Molecular identification revealed that genetic diversity is very high within Giardia species. There are eight basic assemblages, from A-H (Wielinga et al., 2011). The occurrence of A, B, C, and D assemblages was confirmed in dogs, and A, B, $\mathrm{D}$, and $\mathrm{F}$ assemblages found in cats (Adell-Aledón et al., 2018). Assemblages A and B have a zoonotic potential and can infect humans, domestic and wild animals (Fava et al., 2016). Particularly, subgenotypes of assemblages A (subtypes A1, A2, A3, and A4) and B (subtypes B1 and B4) are associated with human infections (Gil et al., 2017). Hence, assemblages A and B are considered zoonotic genotypes (Zhang et al., 2017) and a source of environmental contamination (Piekarska et al., 2016). Genetic assemblages C, D, E, F, and G appear to be host restricted to domestic animals, livestock, and wild animals (Bahrami et al., 2017). Recently, assemblage $\mathrm{H}$ has been diagnosed in marine vertebrates (Feng and Xiao, 2011, and Ryan and Cacciò, 2013). 
There is an absence of epidemiological evidence to show Giardia assemblages infecting dogs in the Kurdistan region with low levels of endemicity. This study aimed to analyze the genotypic prevalence of G. lamblia in symptomatic and asymptomatic dogs.

\section{MATERIALS AND METHODS}

\section{Fecal Specimen Collection}

The present study was performed on 153 stray dogs live in and around rural and street of the town, 92 dogs caught in the evening, tied and fresh fecal samples collected next day from Erbil city. The fecal samples were tested with the naked eye for color, consistency, and the presence of any adult helminths. They were then examined by centrifugal flotation tests for the presence of Giardia cyst stages and the detection of other parasite stages. The technique used in this study was the Sheather's sucrose floatation method. From December 2017 to December 2019, out of 153 fecal samples, 89 specimens whose hosts had diarrhea were got and 64 specimens whose hosts did not exhibit diarrhea. Fecal samples were obtained, numbered in plastic containers. Information on the sex, living area of each dog was reported to find out the risk factors of giardiasis. Fecal specimens were transferred in refrigerated boxes to the laboratory and then stored at $-20^{\circ} \mathrm{C}$ until use.

\section{Parasite Examination (Flotation Methods)}

Approximately $4 \mathrm{~g}$ of the fecal sample was washed with distilled water $(10 \mathrm{ml})$, filtered through doubled gauze, and then centrifuged (1000 $\mathrm{rpm}$ for $5 \mathrm{~min}$ ). These procedures were repeated 3 times, poured the supernatant fluid, added Sheather's sugar solution (Specific gravity $=1.28$ ) is higher than from specific gravity of cyst of $G$. lamblia (AlFahadawi et al., 2017), thoroughly mixed and centrifuged again for further $5 \mathrm{~min}$ at $1000 \mathrm{rpm}$, using a wire loop for removed the top of the centrifuge tube, and put it on a glass slide and applied a coverslip for examination.

\section{Molecular Study}

The molecular analysis was carried for none preservatives samples. The genomic DNA of G. lamblia was extracted using a QIAamp DNA Stool Mini Kit (Qiagen, Germany) according to the manufacturer instructions. Final elutions of DNA were made in $100 \mu$ l. PCR was amplified using Go Taq (Promega, Madison, WI, USA). To define the species and genotyping of extracted DNA fragment; using $\beta$-giardin, the Primer sequence forward and reverse (G7 F5' AAGCCCGACGACCTCACCCGCAGTGC-3' and G759R 5'GAGGCCGCCCTGGATCT'TCGAGACGAC-3') to amplify 753 bp for the G. lamblia (Gultekin et al., 2017). The amplification reaction mixture $(50 \mu \mathrm{l})$ consisted of $25 \mu \mathrm{l}$ of $(\times 2)$ Go-Tag Master Mix, $20 \mu \mathrm{M}(2 \mu \mathrm{l})$ of each primer (forward and reverse), $2 \mu$ of template DNA, and $19 \mu \mathrm{l}$ nuclease-free water. The amplification reaction was carried out using AB Applied Biosystem thermocycler (Veriti 96 Well Thermal Cycler, Singapore), under the following conditions: A pre-amplification step at $95^{\circ} \mathrm{C}$ for $5 \mathrm{~min}$, followed by 35 cycles with denaturing at $95^{\circ} \mathrm{C}$ for the $30 \mathrm{~s}$, annealing at $60^{\circ} \mathrm{C}$ for $30 \mathrm{~s}$ and extension at $72^{\circ} \mathrm{C}$ for $1 \mathrm{~min}$, and the final elongation of DNA strands, an ending extension at $72^{\circ} \mathrm{C}$ for $7 \mathrm{~min}$. Water instead of DNA was included in each set of PCR reactions as a negative control. The PCR products were visualized using 2\% agarose gel electrophoresis (Promega, USA) at 70 Volts, run for approximately $15 \mathrm{~min}$ initially to move slowly after that increased to 100 volts for $45 \mathrm{~min}$ in $\times 1$ TAE buffer (2M Tris-acetate, $50 \mathrm{mM}$ EDTA), prepared by Cleaver Scientific Company, U.K. All PCR products were submitted commercially to sequencing using the same primers $\beta$-giardin (Macrogen EZ-Sequence, Amsterdam, Netherlands) in both directions.

\section{Data Analysis}

Statistical analysis of the epidemiological study was performed using the t-test and Chi-square $\left(\chi^{2}\right)$ test to determine the probability value ( $P$-value) using the GraphPad (6.1). A total of 20 samples were sequenced to determine the intraspecific genotype. Pairwise/multiple sequence alignments and sequence similarities were calculated using the CLUSTALW (Thompson et al., 1997) and the identity matrix options of Bioedit (Hall, 1999), respectively. The sequencing was done using the National Center for Biotechnology Information BLAST programs and databases (Accelrys/Accelrys Gene 2.5) (http:// accelrysgene.software.informer.com/). The obtained results of sequencing were analyzed by comparing the sequence of individual genotypes of G. lamblia with BLAST NCBI (http:/ /blast.ncbi.nlm. nih.gov) database under the accession number M36728 (Holberton et al., 1998) and YA072723 (Caccio et al., 2002).

\section{RESULTS}

Table 1 shows the number of giardiasis in dogs in Erbil Province, during the period from December 2017 to December 2019. The analysis of these data indicates that the number of giardiasis during this period was 16 cases in the fecal centrifugal flotation test and 36 cases by PCR techniques with approximately $(10.46 \%$ and $23.53 \%)$, respectively. Regarding the residency, the infection rate in dogs in the rural area was higher as compared to that of the urban area ((22/153) $14.38 \%$ and (14/153) $9.15 \%$, respectively). These differences were statistically significant $(P=0.0183)$. 
The highest rate of giardiasis was found in males, which was $16.34 \%(25 / 153)$ versus $7.19 \%(11 / 153)$ in females. According to fecal consistency, the rate of infection was higher in diarrheic dogs $18.3 \%(28 / 153)$ than in nondiarrheic dogs 5.23\% (8/153).

Sequence analysis for 20 isolates was successfully performed on PCR products of G. lamblia. The obtained result (MN629930 and MN629931) compared with the previously published sequences under accession number M36728 (Holberton et al., 1998) and YA072723 (Caccio et al., 2002) which is partial sequences, as shown in Figure 1.

Out of 20 isolates, 16 fecal samples (dog 1, 2, 3, 5, 7, $9,11,12,13,14,15,16,1718,19$, and 20) under the accession number (MN629930) showed 100\% identity to G. lamblia GenBank ID: M36728 (Assemblage A1) and four isolates ( $\operatorname{dog} 4,6,8$, and 10$)$ under the accession number (MN629931) showed 99.6\% identity with G. lamblia due to nucleotide changes $(\mathrm{C} \rightarrow \mathrm{T})$ at position 542 and 561 and $(\mathrm{A}$ $\rightarrow \mathrm{G})$ at position 684. The similarity between MN629931 and YA072723 was 99.9\%. One nucleotide substitutions distinguished at position $542(\mathrm{C} \rightarrow \mathrm{T})$, as shown in Figure 1. Among reference strains belonging to assemblage A, two different genotypes (A1 and A2) were identified, which differed for only $2(0.3 \%)$ nucleotide substitutions (Caccio et al., 2002). The tree was constructed using the MEGA-6 software program depending on the neighborjoining algorithm. The phylogenetic tree depending on the multiple sequence alignments (MN629930 and MN629931) with the references (HQ179590 (Wielinga et al., 2011), XM_001705373 (Morrison et al., 2007), EU014386 (Teodorovic et al., 2007), X85958 (Holberton and Marshall, 1995), KM190700 (Prystajecky et al., 2015), EU014393 (Teodorovic et al., 2007), GU396696 (Solarczyk et al.,

\begin{tabular}{|c|c|c|c|c|c|}
\hline Variables & $\begin{array}{l}\text { No. } \\
\text { of } \\
\text { dogs } \\
(153)\end{array}$ & $\begin{array}{l}\text { Positive } \\
\text { no. fecal } \\
\text { centrifugal } \\
\text { flotation } \\
\text { test }\end{array}$ & Percentage & $\begin{array}{c}\text { Positive } \\
\text { no. by } \\
\text { PCR }\end{array}$ & Percentage \\
\hline \multicolumn{6}{|l|}{ Address } \\
\hline Urban & 90 & 5 & 3.27 & 14 & 9.15 \\
\hline Rural & 63 & 11 & 7.19 & 22 & 14.38 \\
\hline \multicolumn{6}{|l|}{ Gender } \\
\hline Male & 99 & 10 & 6.54 & 25 & 16.34 \\
\hline Female & 54 & 6 & 3.92 & 11 & 7.19 \\
\hline \multicolumn{6}{|c|}{ Fecal consistency } \\
\hline Diarrheic & 89 & 14 & 9.15 & 28 & 18.30 \\
\hline $\begin{array}{l}\text { Non- } \\
\text { diarrheic }\end{array}$ & 64 & 2 & 1.31 & 8 & 5.23 \\
\hline Total & 153 & 16 & 10.46 & 36 & 23.53 \\
\hline
\end{tabular}

2010), YA072723 (Caccio et al., 2002), KY612243 (Nunes et al., 2018), and FJ560591 (Bonhomme et al., 2011)) for the classification, as shown in Figure 2.

\section{DISCUSSION}

This study for the $1^{\text {st }}$ time investigated dog giardiasis in Erbil Province; applied flotation technique and molecular detection to identify $G$. lamblia from fecal samples (AlFahadawi et al., 2017). Floatation techniques are unable to differentiate between the genetic assemblages of $G$. lamblia isolates and might not be sensitive enough to detect low numbers of excreted Giardia cysts in fecal samples (Rayani et al., 2014). The overall occurrence of Giardia in this study was found to be $(10.46 \%$ and $23.53 \%)$ flotation and PCR methods. The rate of infection among stray dogs could be related to many factors such as poor health hygiene, climatic conditions (Naser and Wadood, 2017), and the immunosuppressive effects of stress (Palmer et al., 2008) which is partially in agreement with studies in Brazil (Flávio et al., 2011), in Italy (Marangi et al., 2010 and Pipia et al., 2014), and in Poland (Piekarska et al., 2016). The infection rate in dogs in the rural area was higher as compared to that of urban areas $(14.38 \%$ and $9.15 \%$, respectively). Based on molecular identification (PCR), the result is agreed with Inpankaew et al. (2014) in Cambodia, who showed that the prevalence rate was 10.6\% (10/94) by molecular analysis in a rural area. The fact that Giardia spp. was more transmissible from rural due to contact with the rural population and other pets and the high level of environmental fecal contamination with Giardia cysts. Furthermore, the rate of transmission increased through the ingestion of contaminated water or food (Puebla et al., 2015). Consequently, the highest rate of Giardiasis was found in males, which was $16.34 \%$ (25/153) versus $7.19 \%(11 / 153)$ in females. This is in agreement with Gultekin et al. (2017), in Turkey using $\beta$-giardin gene, who documented that the highest rate of infection was found in males $(56 / 257,21.7 \%)$ and the lowest rate was found in the female which was $33 / 216,15.2 \%$. This may be related to the immune status, the living condition of the animals, the design of the study, diagnostic techniques, location, and climatological conditions. On the other hand, the present results disagreed with Bianciardi et al., 2004, who showed that more prevalent in females $(14 / 50,28 \%)$ than in males $(6 / 55,10.90 \%)$ and Tangtrongsup et al. (2017) in Thailand who reported higher prevalence rates in females than males (60.6\% and $31.2 \%$ ); respectively. As well as, the rate of infection was higher in diarrheic dogs $(18.3 \%$, $28 / 153)$ than in non-diarrheic dogs $(5.23 \%, 8 / 153)$ these in agreed with Gultekin et al. (2017) who revealed that the rate of infection was higher in diarrheic dogs $(24.6 \%, 78 / 316)$ than in non-diarrheic dogs $(10.2 \%, 11 / 157)$. Diarrhea is 


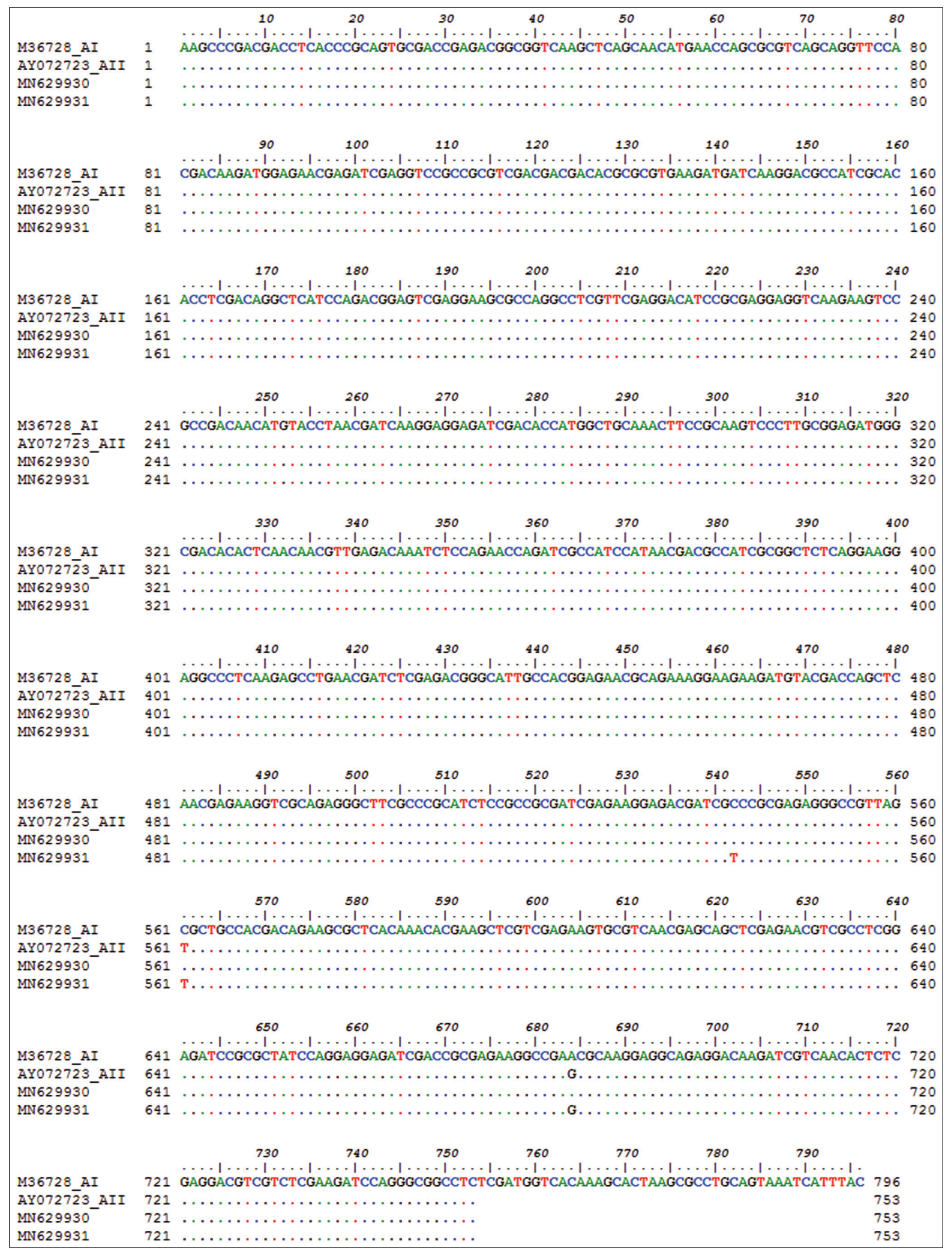

Figure 1: Representative variable regions of partial nucleotide sequences of 753 bps fragment of Giardia lamblia isolated from stray dogs in Erbil Province 


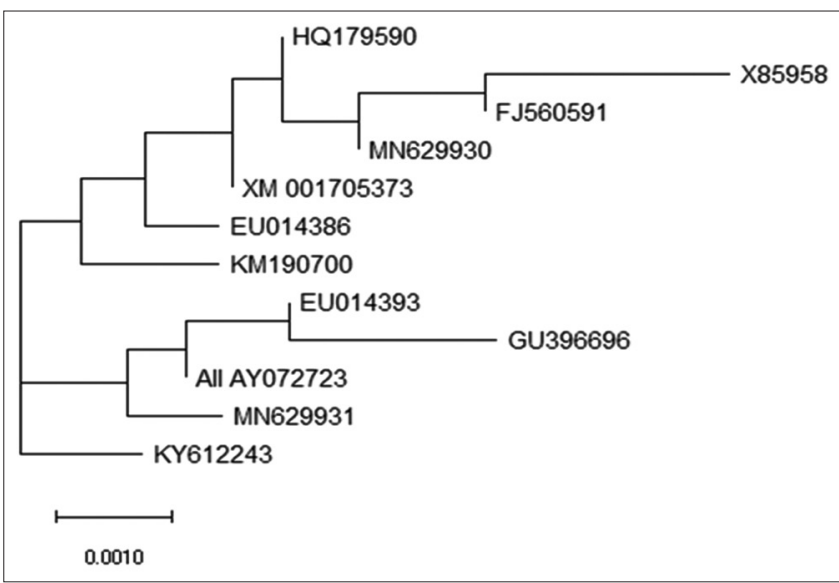

Figure 2: Phylogenetic tree of representative sequences of G. lamblia and references sequences of other genotype and species of Giardia deposited in GenBank

the most common symptom of giardiasis. Several studies have revealed higher prevalence rates of infection in dogs with diarrhea (Upjohn et al., 2010, and Pipia et al., 2014).

PCR was used to amplify the genes which were highly sensitive as a screening tool for Giardia directly from faces and is the traditional gene sequence used for identification and phylogenetic analyses (Traub et al., 2004). The alignment of MN629930 showed 100\% identity with the published sequences of A derived from hosts such as EU014386, FJ560591, HQ179590, and XM_001705373 (Morrison et al., 2007; Teodorovic et al., 2007; Wielinga et al., 2011; and Bonhomme et al., 2011). Also had single nucleotide substitutions $(\mathrm{C} \rightarrow \mathrm{A})$ at positions 99 (EU014390) from human in the USA (Teodorovic et al., 2007) and had two nucleotide substitutions with KY612243 $(\mathrm{C} \rightarrow \mathrm{A})$ at positions 542 and $(\mathrm{A} \rightarrow \mathrm{G})$ at 665 (Nunes et al., 2018). Furthermore, the alignment of EU642896 (Pipia et al., 2014), KM190678 (Prystajecky et al., 2015), and EU014393 (Teodorovic et al., 2007) as assemblage A2 had nucleotide substitutions with our result (MN629931) at positions 438, 587, and $599(\mathrm{C} \rightarrow \mathrm{T})$, respectively. All these authors stated that assemblage $\mathrm{A}$ is the predominant strain affecting dogs and humans. However, the present study has some limitations because most cases were in adult stray dogs. Giardiasis can occur as a mixed infection with other pathogens with the more acute course and can, therefore, remain undiagnosed. The result was partially agreed with Gultekin et al., 2017, who revealed that 38 samples were assemblage $\mathrm{A}(n=38,42 \%)$ and Marangi et al., 2010, who discovered that molecular characterization of Giardiapositive samples from children and dogs showed 99.5\% identity with Giardia assemblage A1.

The phylogram showed that assemblage A from this study was placed in the same clade with all other sequences in this phylogenetic tree. As well as, the long branch length revealed that Giardia assemblages A1 and A2 obtained in this study have a low degree of genetic divergence concerning the other selected sequences obtain in a gene bank, which suggests that geographical location could be the reason for this difference in divergence.

\section{CONCLUSION}

This study may prove useful in the future in understanding the etiology of the disease. Molecular analysis in this study revealed that assemblage $\mathrm{A}$ is the most common type of stray dogs. Giardiasis in Erbil Province is a zoonosis. Molecular identification of Giardia isolates from dog and control programs is recommended to prevent the spreading of giardiasis in humans and animals.

\section{ACKNOWLEDGMENTS}

The author is grateful to all staffs of Erbil Polytechnic University during sampling and methodological procedures.

\section{REFERENCES}

Adell-Aledón, M., P. C. Köster, A. Lucio, P. Puente, M. H. Mingo, P. Sánchez-Thevenet, M. A. Dea-Ayuela and D. Carmena. 2018. Occurrence and molecular epidemiology of Giardia duodenalis infection in dog populations in eastern Spain. BMC. Vet. Res. 14: 26.

Al-Difaie, R. S. 2016. Molecular study to detect genotyping of Giardia lamblia from human and cattle feces in Al-Qadisiya Governorate, Iraq. Ibn Al-Haitham J. Pure Appl. Sci. 29(3): 1-13.

Al-Fahadawi, S. M., S. F. Al-Ani, G. Yusra and Y. G. Yaseen. 2017. Detection of genotypes for Giardia lamblia in Iraqi patient's feces by using PCR-RFLP techniques based on GDH gene characterization. J. Univ. Anbar Pure Sci. 11(2): 18-24.

Bahrami, F., G. H. Zamini, A. Haghighi and M. B. Khademerfan. 2017. Detection and molecular identification of human Giardia isolate in the West of Iran. Biomed. Res. Indian. 28(13): 5687-5692.

Bianciardi, P., R. Papini, G. Giuliani and G. Cardini. 2004. Prevalence of Giardia antigen in stool samples from dogs and cats. Rev. Méd. Vét. 155(8-9): 417-421.

Bonhomme, J., L. Goff, V. Lemée, G. Gargala, J. J. Ballet and L. Favennec. 2011. Limitations of tpi and bg genes sub-genotyping for characterization of human Giardia duodenalis isolates. Parasitol. Int. 60(3): 327-330.

Cacciò, S. M., M. Giacomo and E. Pozio. 2002. Sequence analysis of the $\beta$-giardin gene and development of a polymerase chain reaction-restriction fragment length polymorphism assay to genotype Giardia duodenalis cysts from human fecal samples. Int. J. Parasitol. 32(8): 1023-1030.

Caccio, S. M., R. C. A. Thmpson, J. Mc.Laughlin and H. V. Smith. 2005. Unraveling cryptosporidium and Giardia epidemiology. Trends Parasitol. 21: 430-437.

Faria, C. P., G. M. Zanini, G. S. Dias, S. Silva and C. S. Maria. 2016. Molecular characterization of Giardia lamblia: First report of assemblage $b$ in human isolates from Rio de Janeiro (Brazil). 
PLoS One. 11(8): e0160762.

Fava, N. M. N., R. S. Soares, L. A. M. Scalia, M. J. R. Cunha, E. S. M. Faria and M. C. Cury. 2016. Molecular typing of canine Giardia duodenalis isolates from Minas Gerais, Brazil. Exp. Parasitol. 161: 1-5.

Feng, Y. and L. Xiao. 2011. Zoonotic potential and molecular epidemiology of Giardia species and giardiasis. Clin. Microb. Rev. 24: 110-140.

Flávio, M., P. Silva, M. M. Monobe, R. S. Lopes and J. P. Jr. Araujo. 2011. Molecular characterization of Giardia duodenalis in dogs from Brazil. Parasitol. Res. 109: 1-11.

Gil, H., L. Cano, A. Lucio, B. Bailo, M. H. Mingo, G. A. Cardona, J. A. Fernandez-Basterra, J. Aramburu-Aguirre, N. LopezMolina and D. Carmena. 2017. Detection and molecular diversity of Giardia duodenalis and Cryptosporidium spp. in sheltered dogs and cats in Northern Spain. Infect. Genet. Evol. 50: 62-69.

Gultekin, M., K. Ural, N. Aysul, A. Ayan, C. Balikcia and G. Akyildiz. 2017. Prevalence and molecular characterization of Giardia duodenalis in dogs in Aydin, Turkey. Int. J. Environ. Health Res. 27(3): 161-168.

Hall, T. A. 1999. BioEdit: A user-friendly biological sequence alignment editor and analysis program for Windows 95/98/NT. Nucleic Acids Symp. Ser. 41: 95-98.

Holberton, D. V. and J. Marshall. 1995. Analysis of consensus sequence patterns in Giardia cytoskeleton gene promoters. Nucleic Acids Res. 23(15): 2945-2953.

Holberton, D., D. A. Baker and J. Marshall. 1988. Segmented a-helical coiled-coil structure of the protein giardin from the Giardia cytoskeleton. J. Mol. Biol. 204: 789-795.

Hossain, M. A., S. A. Mina, L. W. Marzan, M. A. K. Emon, R. Das and A. Z. Siddik. 2014. First genotype characterization of Giardia intestinalis assemblage $\mathrm{E}$ from Goat Kids in Bangladesh. Vet. Sci. Technol. 5: 201.

Inpankaew, T., F. Schär, P. Odermatt, A. Dalsgaard, W. Chimnoi, V. Khieu, S. Muth and R. J. Traub. 2014. Low risk for transmission of zoonotic Giardia duodenalis from dogs to humans in rural Cambodia. Parasit. Vectors. 7: 412.

Marangi, M., F. Berrilli, D. Otranto and A. Giangaspero. 2010. Genotyping of Giardia duodenalis among children and dogs in a closed socially deprived community from Italy. Zoonoses Public Health. 57: e54-e58.

Monis, P. T., R. H. Andrews, G. Mayrhofer and P. L. Ey. 1999. Molecular systematics of the parasitic protozoa Giardia intestinalis. Mol. Biol. Evol. 16: 1135-1144.

Morrison, H. G., A. G. McArthur, F. D. Gillin, S. B. Aley, R. D. Adam, G. J. Olsen, A. A. Best, W. Z. Cande, F. Chen, M. J. Cipriano, B. J. Davids, S. C. Dawson, H. G. Elmendorf, A. B. Hehl, M. E. Holder, S. M. Huse, U. U. Kim, E. Lasek-Nesselquist, G. Manning, A. Nigam, J. E. J. Nixon, D. Palm, N. E. Passamaneck, A. Prabhu, C. I. Reich, D. S. Reiner, J. Samuelson, S. G. Svard and M. L. Sogin. 2007. Genomic minimalism in the early diverging intestinal parasite Giardia lamblia. Science. 317: 1920-1926. Available from: http://www.sciencemag.org.

Naser, A. and I. Abdul Wadood. 2017. Detection of Giardia infection in dogs of Basrah city. Bas. J. Vet. Res. 16(2): 159-171.

Nunes, B. C., D. A. Calegar, M. G. Pavan, L. H. Jaeger, K. J. L. Monteiro, E. R. C. Dos Reis, M. M. Lima, M. N. Bóia and F. A. CarvalhoCosta. 2018. Genetic diversity of Giardia duodenalis circulating in three Brazilian biomes. Infect. Genet. Evol. 59: 107-112.

Palmer, C. S., R. J. Traub, I. D. Robertson, G. Devlin, R. Rees and R. C. Thompson. 2008. Determining the zoonotic significance of
Giardia and Cryptosporidium in Australian dogs and cats. Vet. Parasitol. 154: 142-147.

Piekarska, J., J. Bajzert, M. Gorczykowski, M. Kantyka and M. Podkowik. 2016. Molecular identification of Giardia duodenalis isolates from domestic dogs and cats in Wroclaw, Poland. Ann. Agric. Environ. Med. 23(3): 410-415.

Pipia, A. P., A. Varcasia, C. Tamponi, G. Sanna, M. Soda, B. Paoletti, D. Traversa and A. Scala. 2014. Canine giardiosis in Sardinia Island, Italy: Prevalence, molecular characterization, and risk factors. J. Infect. Dev. Ctries. 8(5): 655-660.

Prystajecky, N., C. K. M. Tsui, W. W. L. Hsiao, M. I. U. Diaz, J. Ho, P. Tang and J. Isaac-Rentona. 2015. Molecular and whole genome characterization of Giardia waterborne isolates: Mixes are common in surface water. Appl. Environ. Microbiol. 81(14): 4827-4834.

Puebla, L. E. J., F. A. Núñez, I. M. Silva, L. R. Rivero, M. M. González, Y. Sutil, L. A. Valdés, I. A. Millán and N. Müller. 2015. Molecular characterization and risk factors of Giardia duodenalis among school children from La Habana, Cuba. J. Parasitol. Res. 2015: 378643.

Rayani, M., N. Z. Unyah and G. Hatam. 2014. Molecular identification of Giardia duodenalis isolates from Fars Province, Iran. Iran. J. Parasitol. 9(1): 70-78.

Roointan, E. S., A. Rafiei, A. R. Samarbaf-Zadeh, A. A. Shayesteh, A. Shamsizadeh and M. P. Borujeni. 2013. Molecular identification of Giardia lamblia isolates from adult human cases in southwest of Iran. Afr. J. Biotechnol. 12(9): 901-906.

Ryan, U. and S. M. Cacciò. 2013. Zoonotic potential of Giardia. Int. J. Parasitol. 43: 943-956.

Solarczyk, P., A. Werner and A. C. Majewska. 2010. Genotype analysis of Giardia duodenalis isolates obtained from humans in West-Central Poland. Wiad. Parazytol. 56(2): 171-177.

Tangtrongsup, S., A. V. Scorza, J. S. Reif, L. R. Ballweber, M. R. Lappin and M. D. Salman. 2017. Prevalence and multi-locus genotyping analysis of Cryptosporidium and Giardia isolates from dogs in Chiang Mai, Thailand. Vet. Sci. 4(26): 1-10.

Teodorovic, S., J. M. Braverman and H. G. Elmendorf. 2007. Unusually low levels of genetic variation among Giardia lamblia isolates. Eukaryot. Cell. 6(8): 1421-1430.

Thompson, J. D., T. J. Gibson, F. Plewniak, F. Jeanmougin and D. G. Higgins. 1997. The Clustal-X windows interface: Flexible strategies for multiple sequence alignment aided by quality analysis tools. Nucleic Acids Res. 25: 4876-4882.

Traub, R. J., P. T. Monis, I. Robertson, P. Irwin, N. Mencke and R. C. Thompson. 2004. Epidemiological and molecular evidence supports the zoonotic transmission of Giardia among humans and dogs living in the same community. Parasitology. 128(3): 253-262.

Upjohn, M., C. Cobb, J. Monger, T. Geurden, E. Claerebout and M. Fox. 2010. Prevalence, molecular typing and risk factor analysis for Giardia duodenalis infections in dogs in a central London rescue shelter. Vet. Parasitol. 172: 341-346.

Wielinga, C., U. Ryan, R. D. A. Thompson and P. Monis. 2011. Multilocus analysis of Giardia duodenalis intra-Assemblage B substitution patterns in cloned culture isolates suggests sub Assemblage $B$ analyses will require multi-locus genotyping with conserved and variable genes. Int. J. Parasitol. 41: 495-503.

Zhang, Y., Z. Zhong, L. Deng, M. Wang, W. Li, C. Gong, H. Fu, S. Cao, X. Shi, K. Wu and G. Peng. 2017. Detection and multilocus genotyping of Giardia duodenalis in dogs in Sichuan Province, China. Parasite. 24: 31. 